\title{
INCUMPLIMIENTO POR INHABILIDAD DE OBJETO E INDEMNIZACIÓN DE DAÑOS. COMENTARIO DE LA SENTENCIA DE LA CORTE SUPREMA DE 31 DE OCTUBRE DE $2012^{1}$
}

\author{
BREACH OF CONTRACT, LACK OF CONFORMITY AND DAMAGES. \\ COMENT ON A SUPREME COURT DECISION OF OCTOBER 31, 2012
}

\author{
IŃIgo de La MaZa GaZmuri* \\ Álvaro Vidal Olivares ${ }^{*}$ \\ Antonio Manuel Morales Moreno ${ }^{* *}$
}

\begin{abstract}
RESUMEN: En la sentencia que comentamos, la Corte Suprema, en nuestra opinión, continúa consolidando una cierta doctrina acerca del incumplimiento contractual, cercana a la comprensión propia de lo que se ha denominado el "nuevo derecho de las obligaciones". Igualmente, la sentencia nos suministra una valiosa ocasión para reflexionar acerca de la compleja y, a nivel nacional, más bien inexplorada, cuestión de los daños derivados del incumplimiento contractual.
\end{abstract}

Palabras clave: Incumplimiento contractual, interpretación del contrato, indemnización.

ABSTRACT: From our point of view, in this decision, the Supreme Court sustains certain understanding about breach of contract related to the so called "new law of obligations". The decision also provides a worthwhile occasion to think on the complex and, on a national level, mostly unexplored issue of damages from breach of contract.

Key words: Breach of contract, interpretation, damages.

\section{LOS HECHOS}

La sentencia que comentamos resuelve un caso en el que, en un contrato de compraventa, se discute si un determinado nivel de concentración de níquel en los rodillos de laminación, en desuso, vendidos, está o no incorporado al contrato. De la supuesta incorporación se derivan importantes consecuencias; entre otras, la vendedora no habría entregado

\footnotetext{
1 Zorin S.A. con Compañia Siderúrgica Huachipato S.A. (2012).

* Abogado; Doctor en Derecho; Profesor Investigador Facultad de Derecho de la Universidad Diego Portales; Profesor de Derecho Civil; Correo electrónico: inigo.delamaza@udp.cl. Este artículo se enmarca en el Proyecto Fondecyt regular $\mathrm{n}^{\circ}$ 1120548. El tratamiento de las entregas defectuosas en el derecho chileno: hacia una noción de incumplimiento amplia y unitaria. También participa en el Proyecto español DER2011-24293.

* Abogado; Doctor en Derecho; Profesor Investigador Facultad de Derecho de la Pontificia Universidad Católica de Valparaíso; Profesor Titular de Derecho Civil; Correo electrónico: alvaro.vidal@ucv.cl. Este artículo se enmarca en el Proyecto Fondecyt regular No 1120708. También participa en el Proyecto español DER2011-24293.

** Catedrático emérito de Derecho civil, Universidad Autónoma de Madrid; Profesor Extraordinario de la PUCV; Académico de número de la Real Academia de Jurisprudencia y Legislación, España; Investigador Principal Proyecto de investigación español DER2011-24293.
} 
un objeto conforme a las exigencias pactadas; la falta de conformidad determinaría daños para la compradora que habrían de ser indemnizados, en especial, el lucro cesante.

Los hechos que se tuvieron por acreditados en el proceso son los siguientes: "1․ Que en octubre del año 2006, el señor Luis Acosta, quien hacía de intermediario entre las partes de este juicio, se contactó con don Francisco Barriga, jefe de la unidad de materiales de Compañía Siderúrgica Huachipato S.A., y este último le ofertó la compraventa de chatarra e insumos químicos de una cantidad de rodillos en desuso. Oferta que se materializó mediante la exhibición de una planilla, en la que se individualizan y aparecen las características y composición química de los mentados rodillos.

$2^{\circ}$. Dentro de esta nómina, aparecen unos rodillos con un contenido del elemento químico níquel mayor al de otros rodillos del mismo listado, según se desprende de la simple lectura de la planilla.

$3^{\circ}$. Entre las Empresas Receptoras de la oferta, se encuentra la Sociedad demandante, la que, una vez analizada la planilla por medio de la cual se ofertaron los rodillos, demuestra interés solo por aquellos rodillos en los cuales el contenido de níquel era mayor.

La sociedad demandante aceptó condicionalmente la oferta sobre aquellos rodillos individualizados con mayores niveles de níquel, perfeccionándose el contrato de compraventa solo respecto de los rodillos de las series $8 \mathrm{~B}, 8 \mathrm{C}$ y 12 , en desuso, respecto de los cuales solicitó al señor Barriga las características físicas y composición química”.

De esta narración de los hechos nos interesa resaltar algunos aspectos.

1. La empresa demandante no fue contactada directamente por el vendedor o alguno de sus agentes, sino por un intermediario.

2. El objeto de la oferta se materializa mediante la exhibición de una planilla, en la que se individualizan y aparecen las características y composición química de los rodillos.

3. En la citada planilla se asignó a algunos de esos rodillos un contenido de níquel mayor al de los otros.

4. Entre las sociedades a quien se dirigió la oferta por el intermediario se encontraba la empresa compradora, demandante. Ella muestra interés, únicamente, por aquellos rodillos en los que la concentración de níquel era mayor; y concreta su aceptación de manera condicional, limitada a los rodillos que reunían tal concentración.

5. Tras la aceptación condicional, la compradora solicitó al representante de la vendedora las características y composición química de los rodillos.

6. Finalmente, podemos añadir, según sostiene la demandante, los rodillos suministrados carecían del nivel de níquel que esta había entendido ofertado; lo cual los hacía no aptos para el destino comercial que pretendía darles: la reventa a una empresa estadounidense. 
Al hilo de los hechos descritos, se plantean las cuestiones jurídicas siguientes:

1. El nivel de níquel de la chatarra vendida, buscado por la compradora ¿se encuentra realmente incorporado al contrato? $\mathrm{O}$, lo que es lo mismo, ¿vincula, de algún modo, al vendedor?

2. En la medida en que aceptemos tal incorporación (cosa que la sentencia admite), surge una nueva cuestión: ¿Qué valor (calificación jurídica) hemos de dar a ciertas manifestaciones de la conducta de cada una de las partes, desarrollada bien en el momento de la celebración del contrato o en la fase de ejecución del mismo, puesto que esa calificación determina el régimen jurídico aplicable? Concretamente, al dolo que atribuye la compradora a su contraparte, por el conocimiento que esta tenía de la no conformidad del objeto; o a la culpa que la vendedora imputa a la compradora, por haber omitido verificar las cualidades de la cosa vendida. Esta conducta culposa, según la vendedora, incide no solo en la entidad de los daños, sino antes, en el propio incumplimiento.

3. En conexión con lo anterior se nos presenta la cuestión básica en este caso, referente a los daños que deban ser indemnizados. Cuestión que, siguiendo el método generalmente utilizado, podemos desdoblar en estas otras dos: (1) ¿El vendedor está obligado a indemnizar al comprador los daños relacionados con las características del objeto vendido? ¿Cómo se articulan los factores, anteriormente enumerados (incorporación y conducta de una y de otra parte), en la determinación de si existe o no tal deber de indemnizar? (2) Y, en el supuesto de que este deber exista, ¿qué daños, de los causados al comprador, le han de ser indemnizados?

De entre todas las cuestiones que plantea este caso, nos inclinaremos por centrar nuestra atención, con cierto detenimiento, en la última: la procedencia de indemnización de daños y la medida de los mismos. No obstante, habida cuenta del interés que ofrece la fundamentación de la sentencia en otros aspectos, vamos a referirnos, previamente, aunque sin la profundidad deseada, a los más relevantes, directamente conectados, por cierto, con el núcleo de este trabajo.

\section{ALGUNOS ASPECTOS RELEVANTES DE LA FUNDAMENTACIÓN DE LA SENTENCIA}

Hemos detectado tres aspectos jurídicos de interés en la fundamentación de esta sentencia, a los que nos referiremos brevemente.

\subsection{LA EXIGENCIA DE UNA DETERMINADA CONCENTRACIÓN DE NÍQUEL: INTERPRETACIÓN E INTEGRACIÓN DEL CONTRATO \\ Como se lee en el considerando sexto de la sentencia de reemplazo, la Corte Supre-} ma entendió incorporada al contrato la exigencia de una concentración de níquel ${ }^{2}$, fundándose, aparentemente, en una nota de venta extendida por la demandada y en la cual se

2 Sobre la vinculación del vendedor en cuanto a las cualidades de la cosa, ver Morales (2012). 
especificaba que la venta era de 1.500 toneladas de rodillos de laminación en desuso. A este antecedente podemos añadir la declaración de dos trabajadores de la demandada y un correo electrónico de su representante, con una minuta adjunta que indicaba el detalle de los componentes de los rodillos y que estos contaban con un alto índice de níquel: el requerido por la compradora.

Por su parte, la defensa de la demandada había sostenido, sin éxito, que el objeto de la compraventa consistía en 1.500 rodillos de laminación en desuso y que estos debían ser entregados en el estado en que se encontraban al momento de realizarse la tradición. Y añadió que jamás fue un elemento esencial del contrato el hecho de que tales rodillos tuvieran un alto contenido de níquel o sirviesen para el uso considerado por la empresa compradora.

Hemos de advertir que, en este caso, no existe un documento contractual del que pueda desprenderse, de manera directa e inequívoca, la incorporación al contrato de la cualidad en discusión. Lo que existe, más bien, son documentos propios de la etapa prenegocial por medio de los cuales se van perfilando el acuerdo y los contenidos contractuales; y que llevan directamente a la ejecución de la convención. Esta circunstancia no debiera sorprendernos, pues es bien frecuente en la práctica mercantil.

A pesar de ello, la incorporación al contrato del nivel de níquel, como cualidad de su objeto, no ofrece mayor discusión desde que el propio Tribunal, a pesar de la resistencia u oposición de la vendedora, la da por establecida. Y así, podemos leer en el considerando primero de la sentencia de reemplazo:

"Que la acción deducida en estos autos está referida a un incumplimiento contractual de parte de la vendedora y que el demandante hace consistir en que la cosa entregada tenía unas características distintas a las que había convenido pues, mientras las 1.500 toneladas de rodillos de laminación en desuso se acordó debían contener una determinada composición química, particularmente de Níquel, resultó acreditado que la primera partida que se vendió a los Estados Unidos, por orden de la compradora, carecía de dicha composición”.

Y el considerado séptimo de la misma sentencia expresa:

"Que esta Corte ha llegado a la convicción que los rodillos no tenían la composición química que se había convenido (...)”.

\subsection{El PROBLEMA DEL CONCURSO ENTRE LAS ACCIONES EDILICIAS Y LAS GENERALES POR INCUMPLIMIENTO DEL CONTRATO \\ El debate sobre este problema ${ }^{3}$ se inserta en el juicio, al oponerse la parte demandada} a acción de indemnización que ejercita la demandante. La demandada opone como excep-

\footnotetext{
3 Sobre la idea de concurso puede consultarse DE LA MAZA (2011). En un apretado resumen, entendemos que existe concurso cada vez que un conjunto de circunstancias configura el supuesto de hecho de dos o más remedios distintos o de remedios y acciones de nulidad. En este caso, el concurso sería entre remedios generales (la acción resolutoria) y específicos (los propios del régimen de los vicios redhibitorios. Para un ejemplo bien elocuente de concurso puede consultarse Cecinas La Preferida con Salinak (2005). En ese caso, la Corte Supre-
} 
ción que este caso debe resolverse aplicando las normas del Código civil correspondientes a los vicios redhibitorios, en las que se establece un plazo de prescripción que ya habría transcurrido al tiempo de la demanda, al tratarse de uno de corto tiempo. A partir de ahí se abre el debate de la otra posible vía de fundamentación utilizada por el demandante: la existencia de incumplimiento del contrato, que justificaría la indemnización conforme las reglas generales de incumplimiento.

El que el Tribunal hubiere rechazado la excepción de prescripción implicaría una calificación, o una tipificación, de este caso en el incumplimiento del contrato. Sin embargo, existe algo más que no debe escaparse, el Tribunal reconoce que la voluntad de la compradora no es la de ejercitar las acciones de saneamiento, sino que el remedio de la indemnización fundado en el incumplimiento contractual.

En la sentencia de la Corte de Apelaciones, el considerando undécimo expresa:

"Que para rechazar esta excepción (la de prescripción) bastará tener presente que no es la acción derivada de los vicios redhibitorios la que ejercitó la demandante en estos autos, no siendo procedente atribuirle la voluntad de ejercer una acción distinta de aquella que expresamente manifestó deducir". Y agrega: "Por lo demás, los argumentos que se plantean dicen relación a la naturaleza jurídica de la acción interpuesta más que al transcurso del tiempo necesario para que opere la prescripción extintiva, resultando improcedente emitir pronunciamiento respecto de dicha materia en este estado del proceso".

Y en el considerando Vigésimo Primero de la sentencia de reemplazo se lee:

"Que en relación con la excepción de prescripción opuesta por la demandada a fs. 755 bis, tampoco será acogida, pues en ella se asume que la acción deducida en autos es la derivada de una indemnización por los vicios redhibitorios del contrato de compraventa, conforme con los artículos 1861, 1866 y 1867 del Código Civil, que no es el caso. Como se ha desarrollado en los considerandos primero a cuarto de esta sentencia de reemplazo, la acción indemnizatoria deducida en autos es la general de la responsabilidad contractual, cuya prescripción es de cinco años. En estos autos hay constancia que el plazo de prescripción de la acción intentada no se cumplió desde el momento que se demandó por el incumplimiento de un contrato celebrado el 10 de mayo de 2007 y el demandado aparece dándose por notificado con fecha 1 de octubre de 2008, por lo que no existe fundamento para alegar la prescripción extintiva de la acción intentada en autos".

La calificación de supuesto de incumplimiento y no de vicio redhibitorio, es muy importante en este caso. Hemos de tener en cuenta que se trata de una venta específica referida a la mercadería, o chatarra, que tiene en su poder el vendedor, y todo el debate gira

ma entiende que existe concurso entre la acción resolutoria y la de nulidad por error; entiende, además, que el comprador puede elegir entre cualquiera de las dos vías. 
en torno a si la concentración de níquel integraba o no una calidad de la cosa, condición esencial para la compradora ${ }^{4}$.

Más allá de la calificación de la pretensión indemnizatoria del demandante, que el Tribunal ha fundado en el incumplimiento del contrato, convendría advertir lo siguiente. Aun en el caso de que la acción indemnizatoria ejercitada fuera la de daños regulada en el Código civil dentro del saneamiento por vicios ocultos ${ }^{5}$, aplicable en los casos de dolo o culpa grave (artículo 1861 del Código civil), la actual interpretación jurisprudencial prevalente, haría inadecuado, en este caso, acoger la excepción de prescripción. Como es sabido, durante cierto tiempo la Corte Suprema aplicaba a dicha acción los plazos limitados de las acciones de saneamiento ${ }^{6}$. Pero, a partir de la sentencia del año 2011 cambió su doctrina en el sentido siguiente ${ }^{7}$ : la acción indemnizatoria que, en caso de dolo o culpa grave del vendedor, puede el comprador utilizar no queda sujeta al plazo limitado de prescripción de las acciones edilicias, sino que se le aplica el plazo general de las acciones que no tienen uno especial señalado ${ }^{8}$.

\footnotetext{
${ }^{4}$ Sobre la importancia de que se trate de un venta de especie o cuerpo cierto para efectos de los vicios redhibitorios puede consultarse Morales (2012).

${ }^{5}$ La cuestión de si puede considerarse que existe aquí un vicio redhibitorio plantea un problema interesante acerca de qué vamos a entender por "uso natural de la cosa". Lo más probable es que en el caso de que los rodillos se dediquen a algo diverso de aquello para lo que fueron construidos no podamos hablar de uso natural, sino de uno determinado por las partes que nos deja fuera del campo operativo del artículo 1858.

${ }^{6}$ Alessandri Rodríguez apunta sobre el particular que, formando parte esta indemnización del saneamiento a que por los vicios redhibitorios el vendedor está obligado y prescribiendo las acciones en los plazos arriba indicados, la acción para exigir la indemnización también prescribe en ellos. AleSSANDRI (2003) 258-259.

7 Véase Sentencia dictada en AGF Alliance Chile Compañia de Seguros Generales S.A. con Comercial Otero S.A. (2008). El considerando undécimo señala que: "La indemnización de perjuicios tiene una entidad independiente que la ley prevé en general, sin que existan razones para vincularla de manera determinante con cada una de aquellas acciones de resolución y rebaja del precio, como tampoco para entenderla accesoria a las mismas, en especial cuando se reclama la reparación de daños morales" y que, "una razón fundamental surge para ello: tanto la teoría clásica, al considerar que la indemnización es la misma obligación cuyo cumplimiento se logra por medio de la justicia en naturaleza o por equivalencia, como la teoría moderna que indica que la indemnizaciones es una nueva obligación, llegan a la conclusión que se trata de una obligación principal, nunca accesoria y con mayor razón no puede ser accesoria del saneamiento, que integra la teoría general de las obligaciones de garantía, las cuales son reconocidamente accesorias;" Y el duodécimo añade: "En efecto, la acción propiamente redhibitoria tiene carácter resolutivo y, conforme al artículo 1489 del Código Civil y la jurisprudencia de esta Corte, la indemnización no está vinculada solo con la resolución o el cumplimiento del contrato, pues, ante el incumplimiento contractual, se puede solicitar únicamente la indemnización de perjuicios, sin que necesariamente corresponda asociarla a dicha resolución o cumplimiento" y, finalmente, el considerando décimo tercero expresa que "De todo lo anterior se puede reiterar que los vicios ocultos pueden dar origen independientemente a las acciones redhibitorias; quanti minoris de indemnizatoria, lo cual guarda concordancia con distintas disposiciones del Código Civil, pero fundamentalmente con la regulación que el mismo Código realiza en relación con la condición resolutoria tácita, que en este caso está reglamentada especialmente. Es por ello que de interponerse ya la acción redhibitoria, ya la quanti minoris, igualmente se puede solicitar la indemnización de perjuicios o, de estimarlo pertinente el comprador, limitar sus pretensiones únicamente a la reparación de los daños". 8 Justificando, con sólidos argumentos históricos, la independencia o el carácter autónomo de la acción de indemnización que el artículo 1861 del Código civil reconoce al comprador GUZMÁn (2007). También prescribe en ellos. AlesSANDRI (2003) 258-259. En esta misma dirección: VidAL (2006) 58-59. También, por lo que se refiere al Derecho histórico español: Morales (1980) 614-616. En ese lugar este autor afirma: "En nuestro derecho histórico se atribuye a la acción de indemnización por dolo del vendedor una naturaleza y régimen independientes de los de las acciones de saneamiento; independencia que la doctrina destaca en la medida en que
} 
2.3. La idea de incumplimiento utilizada, en este caso, por la Corte Suprema, EN CUANTO PRESUPUESTO DE LA INDEMNIZACIÓN DE DAÑOS

1. La Corte Suprema sostiene, en este caso, que ha existido incumplimiento del vendedor, porque ha entregado al comprador "una cosa distinta a la convenida". Debemos llamar la atención sobre lo que implica este razonamiento.

El sistema tradicional del saneamiento estaba construido sobre una distinción entre la cosa misma (que debía ser entregada) y sus posibles vicios o falta de cualidades. Esta distinción fundamentaba la aplicación de dos regímenes jurídicos diferentes ${ }^{9}$. La falta de entrega de la cosa vendida daba lugar a la aplicación de la reglas generales del incumplimiento. La existencia de vicios o falta de cualidades a la aplicación de las relativas al saneamiento.

Esta sentencia integra ambas manifestaciones de la vinculación del vendedor en el deber de prestación del vendedor (estar a lo prometido), lo que le permite aplicar el régimen del incumplimiento del contrato, tanto al caso de falta de entrega como al de ausencia de cualidades de que debe tener la $\cos ^{10}$. Así en los considerandos tercero y cuarto de la sentencia de reemplazo, se lee:

"El referido incumplimiento, como se ha dicho, consistiría en que la demandada habría entregado una cosa distinta a la convenida, lo que habría causado daño a la compradora (...)" (considerando tercero). Y añade "Que conforme el artículo 1828 del Código Civil el vendedor es obligado a entregar lo que reza el contrato, lo que supone un cumplimiento estricto en los términos del mismo, norma que debe complementarse con lo que disponen los artículos 1568 y 1569 del mismo Código. Estas disposiciones describen el pago efectivo como la prestación de lo que se debe, ordenan que el pago se hará "bajo todos los respectos en conformidad al tenor de la obligación", salvo casos especiales contemplados por las leyes, y prescriben que "el acreedor no podrá ser obligado a recibir otra cosa que lo que se le deba ni aún a pretexto de ser igual o mayor valor la ofrecida" ${ }^{11}$.

necesita aplicar un régimen jurídico diferente del de las acciones edilicias a los plazos de prescripción. Se considera que la extinción de las acciones de saneamiento por el transcurso del tiempo, no implica la de la acción de indemnización fundada en el dolo del vendedor".

9 Sobre la diferencia entre obligaciones de especie o cuerpo cierto y de género ver el completo estudio de FenOY (2006).

10 "La exigencia de conformidad de la cosa contenida en (...) la CISG (Convención de Viena, 1980) rompe abiertamente con esa tradición [de los Códigos civiles continentales]. Tras ella subyace un modo distinto de entender el objeto de la obligación del vendedor (...): si el objeto de la obligación es entregar una cosa conforme al contrato, puede afirmarse que el objeto no es la cosa, tal cual es, sino tal como debe ser. Aceptarlo así, permite considerar como un verdadero incumplimiento la entrega de una cosa no conforme.": Morales Moreno (2006) 102.

${ }_{11}$ En este mismo sentido, en lo que concierne a una comprensión amplia de incumplimiento que arranca desde las normas del pago, se halla la sentencia de la Corte de Apelaciones de Concepción de 1 de diciembre de 1993, dictada en recurso de apelación Rol No 1.171 -1992. En su considerando séptimo se lee: “(...)Pero lo que el vendedor ha de entregar es la misma cosa que se individualiza en el contrato y esa obligación solo se cumple si lo entregado es la cosa tal y como ha sido convenida, de forma que, faltándole alguna parte o afectándole algún derecho en favor de un tercero que pueda producir su evicción, el vendedor no ha cumplido cabalmente su obligación;"; y en el octavo, complementa su fundamentaciónn, declarando "(...) En efecto, el vendedor está obligado a entregar lo que reza el contrato, regla dispuesta a propósito de la obligación de entregar (pág. 6 Tít. XXIII, Lib. 
Este es el criterio que va generalizándose en todos los textos normativos del que podemos denominar "nuevo derecho de la contratación", en el que desaparecen los vicios redhibitorios como forma especial de incumplimiento, dando lugar a la absorción del sistema del comprador denominado saneamiento por el régimen general del incumplimiento ${ }^{12}$.

Es cierto que todavía en el Código civil chileno (como en muchos europeos) no se ha producido el cambio normativo que integre las acciones de saneamiento en el régimen general de incumplimiento del contrato. Por el momento, siguen existiendo las acciones de saneamiento; conviven con el nuevo modo de entender el incumplimiento, que decididamente se ha abierto paso. Esto da lugar a que en la práctica sea frecuente que los demandantes fundamenten sus pretensiones tanto en el saneamiento como en el incumplimiento ${ }^{13}$; y que los demandados intenten construir su defensa invocando la prescripción de las acciones de saneamiento, como si no existiera otro sistema. El hecho de que de la falta de conformidad al contrato de la cosa vendida pueda subsumirse en dos sistemas de remedios distintos (incumplimiento o cumplimiento imperfecto del contrato, y saneamiento por vicios) plantea el problema del concurso de acciones, al que nos hemos referido en la sección anterior ${ }^{14}$.

2. Es interesante también destacar cómo la Corte conecta la ausencia de la cualidad que debe tener la cosa (en este caso, una determinada concentración de níquel) con su inhabilidad para el destino o propósito práctico del $\operatorname{contrato}^{15}$ : la finalidad que impulsa al comprador a celebrar el contrato, incorporada al propio contrato (presupuesta en el contrato e incluso, en ocasiones, como en este caso, garantizada por el contrato).

Si el contrato fija, exclusivamente, las cualidades que debe tener la cosa y no se refiere al destino de la misma que garantiza el vendedor, nos encontramos con el problema de concretar, en cada caso, el destino garantizado por el contrato, que vincula al deudor.

IV) y que hace de la obligación de entregar no solamente un paso material y jurídico de la cosa, sino también comprender en ella, una identidad entre aquello que forma el objeto de la obligación y lo efectivamente entregado, puesto que, en definitiva, no se trata sino de la particularización de la regla general del artículo 1569 que impone como requisito objetivo del cumplimiento la exactitud, identidad e integridad de la prestación, pues guarda aún vigencia la fórmula del Derecho Romano aliud pro alio, invito creditori solvi non potest (I.2, 1, D. 1, así, Heredia y Castaño (1956) 209 y ss., El Cumplimiento de las Obligaciones, págs. 209 y sgts. Madrid 1956)”. La misma comprensión del cumplimiento se encuentra en Cecinas La Preferida S.A. con sociedad Comercial Salinak Limitada (2005). Con comentario en Revista Chilena de Derecho Privado, No 6, 2006, pp. 155-162.

${ }_{12} \mathrm{La}$ forma en que estos textos eliminan la presencia de los vicios redhibitorios puede consultarse en VIDAL (2011). Deben considerarse también los artículos del Draft of the Common Frame of Reference y 99 y ss del Common European Sales Law.

13 Ver, por ejemplo, Cecinas La Preferida S.A. con sociedad Comercial Salinak Limitada (2005).

14 Sobre este problema, en Derecho español, Fenoy (1996).

${ }_{15}$ Según Castro, "se tiene en cuenta mejor la verdadera voluntad de los particulares atendiendo al fin práctico del negocio." Y para ilustrarnos lo que esto significa no ofrece un ejemplo muy esclarecedor. Atendiendo a un punto de vista para él criticable, en la compra de una casa, "quedaría extramuros del derecho el propósito práctico del comprador de habitarla o arrendarla, aunque de ello se tratara con el vendedor". En cambio -en su opinión- conforme al fin práctico propuesto (como hacen en sus decisiones los tribunales), se entenderá integrado en el propósito negocial el habitar o arrendar la casa, y consiguientemente quedará viciado el negocio cuando se oculta el mandato de su derribo (por ejemplo, por servidumbre hacia un aeródromo por la zona militar) o la prohibición de arrendar (por ejemplo, respecto a ciertas construcciones protegidas)." MorALEs (1983) p. 1531. 
Adviértase el salto que hay que dar de la exigencia formal de existencia de una cualidad, a la inhabilidad para el destino que pretende darle el comprador.

Un criterio que suele utilizarse para concretar el destino garantizado por el contrato es el del destino usual. Este criterio está presente tanto en los códigos decimonónicos (artículo 1858, No 2 del Código Civil), como en la Convención de Viena sobre compraventa internacional (artículo 35 CISG) ${ }^{16}$. Pero este criterio no sirve en el caso actual. ¿Acaso es usual el que el comprador esté interesado en revender la chatarra comprada a quien solo está interesado en un determinado nivel de concentración de níquel en ella? La compradora, en este caso, argumenta que esos rodillos no admitían otro uso que ser vendidos como metal de una alta concentración de níquel. Y a ello se añade algo importante: los rodillos, como simple chatarra, tendrían otro precio, muy por debajo del convenido. La compradora advierte que ella no se hubiera obligado a pagar un precio tan elevado como el convenido de no haber tomado en consideración, como condición esencial, esa concentración de metal que los hacía idóneos para un destino distinto al que pueda dársele a una mera chatarra. Nótese, por otra parte, que el reproche de incumplimiento dirigido a la vendedora viene exclusivamente fundado en la falta de concentración de níquel establecida en el contrato, en consideración a que tal carencia o ausencia de cualidad impide a la compradora concretar su negocio con la empresa estadounidense.

Extraigamos una conclusión. En muchos casos el paso de la cualidad que debe tener la cosas a la garantía de un determinado destino de la misma es claro ${ }^{17}$; sin embargo, en otros no, resultando necesario proceder a la interpretación del contrato. Cobra entonces un rol gravitante el criterio de la buena fe objetiva del artículo 1546 del Código civil, que actúa como verdadero vehículo de determinación de destinos o finalidades del objeto contractual a partir de una determinada cualidad incorporada al mismo ${ }^{18}$.

\subsection{RECONOCIMIENTO DE LA AUTONOMÍA DE LA PRETENSIÓN INDEMNIZATORIA DE} DAÑOS

1. Esta sentencia se enmarca en una corriente jurisprudencial que está revisando el criterio tradicionalmente sostenido sobre la articulación de la pretensión indemnizatoria con la de cumplimiento y la resolución del contrato $^{19}$. Como es sabido, la Corte Suprema, con apoyo en la doctrina, exigía para reclamar la indemnización de daños y perjuicios, que dicha pretensión fuera acompañada del ejercicio de la pretensión de cumplimiento o de la demanda de resolución del contrato conforme el artículo 1489 del Código Civil. La nueva

\footnotetext{
${ }_{16} \mathrm{Y}$ a ellos podemos añadir el artículo 2) de la Directiva 1999/44/CE del Parlamento Europeo y del Consejo, de 25 de mayo de 1999, sobre Determinados Aspectos de la Venta y las Garantías de los Bienes de Consumo y el artículo 100 del Proposal for a Regulation of the European Parliament and of the Council Common European Sales Law.

17 Si hemos de precisar que en el caso que nos ocupa no hay precisiones respecto al destino de la cosa y que hay que inferirlas aplicando el citado criterio de lo usual u ordinario. En otros casos sí hay cláusula expresa y la resolución judicial es menos conflictiva, como es el caso de la sentencia de la Corte Suprema dictada en Glide Diversiones Limitada con Compañia de Inversiones y Desarrollo Sur S.A. (2008).

${ }_{18}$ La vinculación entre buena fe y propósito práctico ya había sido advertida en BARAONA (1998) pp. 78-79 y Alcalde (2008) pp. 72-73.

19 LÓPEZ (2010).
} 
línea jurisprudencial, con asiento mayoritario en la doctrina contemporánea, autoriza el ejercicio directo y exclusivo de la acción contractual de indemnización de daños; lo que en este caso da lugar a que la indemnización se produzca, manteniendo vigente el contrato ${ }^{20}$.

El argumento que utiliza esta sentencia para justificar la procedencia de la indemnización, conservando el negocio, consiste en el recurso a las normas del pago de las obligaciones; en particular, a la del inciso segundo del artículo 1591 que ordena: "El pago total de la deuda comprende el de los intereses e indemnizaciones que se deban”.

En el considerando noveno de la sentencia de reemplazo se lee:

"Una vez establecido que efectivamente ha existido un incumplimiento del contrato, corresponde determinar si la actora ha podido ejercer la acción indemnizatoria, como lo ha hecho, prescindiendo de lo que disponen los artículos 1489 y 1826 del Código Civil, que parecen indicar que tal acción no es autónoma, sino que siempre debe ir acompañada sea de la petición de resolución contractual o bien de la exigencia del cumplimiento del contrato. Como ya lo ha resuelto la Corte en otras oportunidades, y siguiendo la moderna tendencia doctrinal (Rol 3341-012), se estima que, en este caso, la demandante ha podido plantear su demanda de responsabilidad civil contractual, sin asociarla a la resolución del contrato (...)”.

${ }^{20} \mathrm{La}$ Corte Suprema en su sentencia de 28 de enero de 2013, dictada en causa "José Ampuero Asencio con Alfonso Castillo Hernández" (2013), anula la sentencia de segunda instancia que niega el carácter autónomo de la acción indemnizatoria, expresando lo que sigue: "Que abordando esta última tesitura, y en concordancia con lo razonado en los motivos $1^{\circ}$ y $2^{\circ}$ de este sentencia de reemplazo, todo ello enmarcado en el rol orientador en la aplicación del derecho que le cabe a esta Corte Suprema, debe decirse que respecto de la indemnización de perjuicios pura y simple descartada por la sentencia recurrida, en atención a su carácter accesorio a la resolución o cumplimiento forzado del contrato conforme a los principios que integran el Código Civil, no se observan las particulares motivaciones que podrían inducir a privar a los afectados de dirigir las acciones en la forma y del modo como mejor se ajusten a sus intereses, desde el momento que el derecho civil otorga a las personas el principio de libre disposición de sus bienes y autonomía de la voluntad, todo lo cual lleva a reconocer las mayores prerrogativas al momento de someter las pretensiones al órgano jurisdiccional. Por lo anterior que esta Corte Suprema ha reconocido la independencia y autonomía de las acciones indemnizatorias, sean estas moratorias o perentorias, las que cualquiera sea la naturaleza del objeto de la prestación, pueden impetrarse en forma exclusiva, desde el momento que el legislador ha establecido su procedencia y la forma más usual de interposición, pero no ha prohibido la que en mejor forma repare integralmente el daño derivado del incumplimiento. En efecto, la acción indemnizatoria no se encuentra ligada únicamente en sede contractual a la resolución o cumplimiento forzado de lo pactado, puede entonces cobrar identidad propia, como acción principal, aunque asociada a una de las variantes referidas resolución o cumplimiento forzado, como a ninguna de ellas, sin perjuicio que para ponderar esta pretensión resulta indispensable vincularla con el hecho en que se le hace descansar. Entonces, ante la entidad independiente que la ley prevé en general, no existen razones para vincularla de manera determinante con cada una de aquellas acciones de resolución y cumplimiento, como tampoco para entenderla accesoria a las mismas. Una razón fundamental surge para ello: tanto la teoría clásica, al considerar que la indemnización es la misma obligación cuyo cumplimiento se logra por medio de la justicia en naturaleza o por equivalencia, como por la teoría moderna que indica que la indemnización es una nueva obligación, lo que permite arribar a la conclusión que se trata de una obligación principal, nunca accesoria. En sentido contrario, la interpretación exegética del artículo 1489 del Código Civil deriva de una lectura literal del mismo, se contrapone a la reparación integral del acreedor." 
Y en el considerando décimo agrega:

"Que, en todo caso, una demanda de daños y perjuicios en los términos que se han descrito, debe ser considerada como parte de lo que el vendedor debe en "cumplimiento del contrato", de acuerdo con los términos del artículo 1489 del Código Civil. En efecto, conforme con el artículo 1591, "el pago total de la deuda comprende el de los intereses e indemnizaciones que se deban”. Dado que en este juicio se pretenden indemnizaciones derivadas de un incumplimiento contractual, asociadas a una entrega imperfecta de la cosa vendida, debe entenderse que el deudor está ejerciendo una acción de cumplimiento contractual, para ser debidamente pagado por el deudor, aunque la acción esté reducida a las indemnizaciones que el actor estima que la sociedad demandada le adeuda por incumplimiento de contrato".

2. En los considerandos transcritos debemos destacar: (i) La vía que utiliza la Corte de casación para permitir el ejercicio independiente de la pretensión indemnizatoria, y (ii) la función que asigna a la indemnización en la responsabilidad contractual.

La indemnización se justifica en la exigencia de integridad del pago ${ }^{21}$. La integridad del pago, exigencia del mismo para que el acreedor satisfaga su interés, ya no solo se entiende como ejecución de la obligación pactada, ni tampoco como mero equivalente pecuniario de la prestación adeudada, sino también como satisfacción por vía indemnizatoria, aplicando la regla de la responsabilidad civil de los artículos 1556 y concordantes, todos del Código Civil. Recordemos, ya lo hemos dicho, que, en la responsabilidad contractual, la indemnización debe colocar al acreedor en la misma posición económica que tendría de haberse cumplido el contrato ${ }^{22}$. Por esta razón, la lectura que debemos hacer de la sentencia y, en particular, de los considerandos transcritos, es que la acción de indemnización persigue no el cumplimiento -en equivalencia- sino la satisfacción del interés; que, en este caso, va más allá del referido a la mera entrega de los rodillos y se refiere al destino que el comprador iba a darles, destino garantizado por el contrato. Tanto es así, que la demanda persigue, principalmente, daños que exceden del interés en el objeto de la prestación y se refieren a otros intereses, como el de intercambio y el de indemnidad de la persona del acreedor (honor comercial de la demandante), no obstante solo se de lugar a la indemnización de los daños provenientes de la lesión del primero, por estar incorporado en el contrato ${ }^{23}$.

(ii) Esto implica una profunda revisión de la función de la indemnización. No es, simplemente, un sustituto del cumplimiento o de la prestación prometida, sino una reintegración del acreedor al estado que debería tener de haberse cumplido el contrato. Dicho de otra manera, la satisfacción del interés en el cumplimiento del contrato. De modo que esa

21 Ver Vidal (2014).

22 Ver artículo de los PCCI. La regla es, por lo demás, bastante universal. Ver, por ejemplo, Dí́Ez-PiCAzo (2008) p. 781 y SAIDOV (2008) p. 17-18.

23 Sobre las diferentes manifestaciones del interés indemnizable, en la responsabilidad contractual, MORALES (2010) 38 ss. 
visión nueva del derecho de crédito que pendula desde la idea de deber de prestación hacía la satisfacción del interés del acreedor aquí queda claramente plasmada ${ }^{24}$.

3. Mantener esta idea exige ciertas precisiones. Cuando el contrato se desenvuelve correctamente y el deudor cumple su deber de prestación, el acreedor gestiona como estima conveniente la satisfacción de su interés a partir de la prestación. Pero, cuando el deudor incumple su deber, y procede la indemnización del daño causado, hemos de delimitar cuál es el interés lesionado objeto de indemnización ${ }^{25}$.

El propósito práctico del contrato que delimita su fin de protección de contrato puede servirnos para como criterio para concretar, en cada caso, de ese interés ${ }^{26}$. Y es la idea que subyace en la referencia del artículo 1558 del Código civil, "a los perjuicios que se previeron o pudieron preverse al tiempo del contrato"; artículo este, por cierto, aplicado por la sentencia en este caso para justificar la procedencia de la indemnización del lucro cesante. El fin de protección del contrato hemos de concretarlo, en cada caso, por medio de la interpretación ${ }^{27}$.

Para comprender lo que debe significar el criterio de la previsibilidad, tantas veces invocado y seguramente pocas veces bien precisado, resulta muy ilustrativo tener en cuenta lo que afirma Lord Hoffmann en el caso en el año 2008 se dicta la sentencia Shipping Inc v. Mercator Shipping Inc ${ }^{28}$, resuelto por la Cámara de los Lores durante el año 2008:

"El caso (...) plantea una cuestión fundamental en el derecho de los daños contractuales: la regla según la cual una parte puede obtener indemnización de los daños previsibles, ¡es una regla jurídica externa, impuesta a las partes en cada contrato, en defecto de una provisión en contrario, o una asunción, prima facie, de lo que puede entenderse que han querido las partes, aplicable, sin duda, en la gran mayoría de los casos, pero susceptible de rechazo en los casos en que el contrato, las circunstancias presentes o el criterio general del mercado relevante ponen de manifiesto que no sería razonable entender que un contratante hubiera asumido responsabilidad por tales daños" 29 .

De acuerdo con la idea de Lord Hoffmann, que, por cierto, se aproxima más a la originaria de Pothier $^{30}$, al elaborar el tópico de la previsibilidad, que a la habitual en el de-

\footnotetext{
${ }^{24}$ Conecta con esta nueva visión del contrato lo que en el año 1981 afirmaba Morales (2006) p. 325 en su trabajo, El propósito práctico y la idea de negocio jurídico en Federico de Castro: "[T]odo negocio jurídico [contrato] en sí mismo considerado justifica en quienes lo han celebrado un determinado interés que razonablemente aspiran a ver satisfecho y que, también, por múltiples causas, unas imputables a la conducta de la otra parte y otras no imputables a ella, puede quedar sin satisfacción”. Ver, además, Gatica (1959) p. 27-29 FUEYO (2004) p. 343 Pantaleón (1993) p. 1378, Díez-Picazo (2008) pp. 781-782, Remy (1997) p. 323, Corral (2010) pp. 125, 126 y 141; Carrasco, Bahamondes (2011) p. 235.

25 Morales (2010) p. 32.

26 Sobre este concepto Morales (2010) pp. 93 ss.

27 Morales (2010) pp. 168 ss.

28 UKHL (2008) p. 48.

29 Morales (2010) p. 143-144. Un comentario de la sentencia citada y la evolución de la regla de la previsibilidad en el derecho inglés véase: GreGoraci (2011) pp. 295-312.

30 Morales (2010) pp. 143, 144.
} 
recho angloamericano, el daño indemnizable en nuestro caso hemos de delimitarlo a partir de la incorporación de la cualidad, "concentración de níquel", al contrato y de la utilidad de que la presencia de ella puede razonablemente esperarse que preste al comprador. Y desde luego está dentro del fin de protección del contrato el que el comprador pueda revender la chatarra comprada, asegurando esos mismos contenidos de níquel que a él se le garantizaron, a un precio razonable de mercado.

\section{EL CÁLCULO DE LOS DAÑOS EN LA SENTENCIA DE LA CORTE SUPREMA}

\section{1. ¿Cómo hemos de calcular los daños? Dos supuestos de cálculo de la INDEMNIZACIÓN}

Quizás, una primera observación que hayamos de hacer es que no encontramos en la sentencia una distinción bien frecuente en nuestra práctica entre indemnización compensatoria e indemnización moratoria. Creemos que la Corte reflexiona bien cuando prescinde de ella. La razón es que nos encontramos frente a un supuesto de incumplimiento diverso de la falta de incumplimiento o del retardo del mismo. De esta manera no resultaría técnicamente correcto utilizar cualquiera de las dos categorías.

Advertido lo anterior y para mayor claridad, recordemos las circunstancias básicas de este caso: (a) Se trata de un contrato de compraventa; (b) el objeto son unos rodillos de laminación en desuso con una cierta concentración de níquel; (c) el comprador adquiere los rodillos para revenderlos a otra empresa; (d) la reventa exige que invierta importantes cantidades de dinero para transformar la cosa; y (e) los rodillos entregados carecían de la concentración de níquel garantizada por el contrato, lo que se pone de manifiesto por el rechazo de los mismos por el segundo comprador.

Debemos tener en cuenta, así mismo, la función de la indemnización en la responsabilidad contractual es colocar al acreedor insatisfecho (en este caso al comprador), en la medida de lo posible, en la misma posición "económica” en la que se encontraría si se hubiere cumplido el contrato ${ }^{31}$. Lo cual, como hemos visto, conecta el daño contractual con el fin de protección del contrato.

A partir de lo dicho, en lo que se refiere a la determinación del daño indemnizable, podemos diseñar, como punto de partida, dos modelos básicos, que representan las alternativas extremas relacionadas con este caso.

(i) Supongamos, como primer modelo, que el comprador ha pagado el precio de la mercancía y, además, ha incurrido, por completo, en los costos necesarios para la transfor-

${ }^{31}$ En el mismo sentido puede consultarse el artículo 160 de la Propuesta de Reglamento del Parlamento Europeo y del Consejo relativo a una normativa común de compraventa europea (en adelante, CESL), bajo el título "Criterios generales para el cálculo de la indemnización por daños y perjuicios", cuyo tenor es el siguiente: "El cálculo de la indemnización por pérdidas ocasionadas por el incumplimiento de una obligación se hará de forma que el acreedor quede en la posición en la que se habría encontrado si se hubiera cumplido debidamente la obligación, o de no ser posible, en una posición lo más parecida posible. La indemnización cubrirá las pérdidas que el acreedor haya sufrido y las ganancias que haya dejado de obtener". La idea responde al principio contenido en el parágrafo 249 del BGB. 
mación de ella en el estado en que ha de ser revendida. En esta hipótesis, el daño indemnizable coincide con el precio de la segunda compraventa. Y, de no haber existido esa reventa, el daño indemnizable corresponderá al precio calculado conforme al mercado ${ }^{32}$.

La suma equivalente al precio que hubiera podido obtenerse de la mercancía engloba las siguientes partidas: (1) el costo de adquisición de la mercancía, (2) el costo de su transformación, para ser revendida, y (3) el beneficio o provecho que debería haber obtenido el comprador (revendedor) si no se hubiere frustrado la reventa (por la falta de conformidad de la mercancía). Las tres partidas serían en este modelo indemnizables. Las dos primeras son un daño emergente, la tercera un lucro cesante.

(ii) Imaginemos, como segundo modelo, que el comprador no ha incurrido en los costos anteriormente descritos [bajo el número (1) y (2)]. No ha pagado el precio, ni está obligado a ello, por haber resuelto el contrato. Tampoco ha incurrido en gastos de transformación de la mercancía. En este caso la indemnización se circunscribe al beneficio justificadamente esperado, conforme a la finalidad del contrato (lucro cesante). Puede ser calculada así: será igual al precio fijado en el contrato de reventa - o, a falta de este, el precio de mercado- menos los costos de adquisición y de transformación economizados. En el espacio intermedio entre estos dos modelos son posibles múltiples variantes, según se combinen estos elementos. Lo que nos interesa es constatar el modo en que se combinan en este caso.

\subsection{El CASO, UNA VEZ MÁS}

Para determinar el daño indemnizable y las partidas que lo integran, debemos descender a mayores detalles del caso que nos ocupa.

Se celebra un contrato de compraventa de 1.500 toneladas de rodillos de laminación en desuso, que debían tener cierta concentración de níquel. El precio establecido fue US \$ 267.750. A fin de garantizar el cumplimiento del contrato, la compradora pagó a la vendedora, como anticipo, \$25.000.000 (veinticinco millones de pesos) y procedió al retiro de los rodillos adquiridos. Por su parte, la compradora, celebró un nuevo contrato de compraventa, con una empresa norteamericana. El objeto eran rodillos como los adquiridos, con la misma concentración de níquel considerada en la primera venta. Para dar cumplimiento a la entrega en esta segunda venta, la compradora procedió a cortar la totalidad de los rodillos, en un costoso y complejo proceso que generó un gasto de \$ 70.000 .000 (setenta millones de pesos); y posteriormente, procedió al envío de una parte de los rodillos cortados (58 toneladas) a la empresa norteamericana. Esta empresa, tras este primer embarque, lo rechaza, señalando que la composición del metal enviado distaba enormemente de lo acordado.

Constatado el incumplimiento, la primera compradora demanda a su vendedora las siguientes partidas indemnizatorias ${ }^{33}$ : (i) Por concepto de daño emergente, US \$100.000. Esta suma comprende: el costo del corte de los rodillos solicitados por la empresa extranjera (\$75.000.000), y el anticipo del precio pagado a la vendedora(US \$ 25.000.000). Por lucro cesante, US \$2.220.000, que se descomponen de la siguiente manera: US \$220.000

\footnotetext{
32 Este es el principio inspirador del artículo 76 de la CISG en los casos en que hay resolución del contrato.

${ }^{33}$ La vendedora demanda también lo que denomina "daño moral y de imagen" que no consideraremos aquí y que, en definitiva, no fue concedido.
} 
por pérdida de la ganancia que hubiese obtenido de no haberse frustrado la reventa de las 58 toneladas enviadas a la empresa norteamericana, y US \$2.000.000 por las reventas del resto de los rodillos adquiridos, que celebraría en el futuro con la empresa norteamericana.

\subsection{LAS PARTIDAS INDEMNIZATORIAS CONCEDIDAS}

La pretensión indemnizatoria de la compradora fue rechazada en cuanto al daño emergente:

Que en relación con los rubros que cobra por daño emergente, no procede acogerlos. Lo que se demanda como indemnización por el corte de los rodillos es una acción realizada directamente por el comprador, y en todo caso es un costo propio del negocio que se realizaba, por lo que no procede ser indemnizado, de acuerdo con lo dispuesto en los artículos 1556 y 1558 del Código Civil. Respecto de la indemnización procedente del pago de parte del precio, tampoco se concederá esta indemnización, pues, el demandante no ha pedido la resolución del contrato, que sería la única causa para exigir este dinero a título restitutorio. De la manera que se ha demandado, ha quedado el contrato subsistente y el demandado tiene derecho a mantener los rodillos en su poder, por lo que no se justifica que se le indemnice por el pago parcial del precio en virtud de un contrato de compraventa que se estima válido y cuya resolución no se ha pedido. [Considerando décimo sexto de la sentencia].

En cuanto al lucro cesante, fue admitida, en los términos siguientes:

“...de acuerdo con estos antecedentes, y con la declaración del demandante en su escrito de demanda, la utilidad que debía arrojar este negocio a la fecha de presentación de la demanda era de $\$ 114.400 .000$, monto que estima perfectamente como beneficio o utilidad del negocio y, por lo mismo, se concederá una indemnización por este rubro." [Considerando décimo octavo].

Efectuemos algunas consideraciones críticas al respecto.

¿Es correcta la forma en que la sentencia se hace cargo de las partidas indemnizatorias? Nuestra impresión es que, en este punto, el fallo admite ciertos comentarios. Vamos a hacerlos separando tres rubros: (i) indemnización del costo de adquisición, (ii) de los gastos de transformación, y (iii) de la utilidad o ganancia proyectada.

(i) Indemnización por el costo de adquisición de la mercancía

El Tribunal rechaza considerar como partida indemnizable, ni siquiera la parte de precio pagada por la compradora. Esta solución es acertada, en definitiva; pero conviene profundizar en su justificación o fundamentación jurídica.

Hay que tener en cuenta que, en este caso, a pesar del incumplimiento de la vendedora, la compradora opta por no resolver el contrato, y demandar, exclusivamente, la indemnización de daños. Sigue, por ello, obligada a pagar el precio pactado: en parte ya pagado, por el anticipo, y en cuanto al resto todavía adeudado. 
Pero también es necesario tener en cuenta, a los efectos de calcular la indemnización por la partida del costo de adquisición de la mercancía, que la mercancía adquirida, aunque no sirva para la finalidad establecida en el contrato, seguramente tendrá cierto valor como pura chatarra. Ese valor debe ser descontado del costo de adquisición indemnizable, de lo contrario la compradora se enriquecería injustificadamente. En este caso no sabemos cuál es ese valor, ni el Tribunal lo ha tomado en cuenta, pues el costo de adquisición de la mercancía no ha sido considerado como partida indemnizable.

Recordemos que la compradora solo había pagado una parte del precio total de la mercancía adquirida, como anticipo, estando pendiente de pago el resto. Este saldo impagado constituye, pare ella, una deuda pendiente. ¿Cómo se liquida? En lo que nos interesa, dicha deuda se compensará con la indemnización a favor de la compradora. Esto es lo que parece entender la Corte Suprema en el considerando decimotercero de la sentencia cuando niega lugar a la alegación de la vendedora consistente en una excepción de contrato no cumplido por falta de pago del precio. Señala el Tribunal:

"Debe tenerse presente, en este sentido, que la excepción de incumplimiento contractual debe ser ejercida siempre de una manera proporcionada, calidad que la excepción de incumplimiento opuesta por la demandada no reúne, desde el momento en que la excepción que opone no es apropiada para oponerse a que este tribunal pueda valorar los perjuicios derivados de la entrega imperfecta de la cosa comprada. Distinto es que, después de determinada la indemnización a favor de la actora, se compensen total o parcialmente las respectivas obligaciones, en caso que corresponda”.

Aplicar la compensación como método de liquidación de la deuda pendiente por el precio de la mercancía determina que la compradora no reciba, en este caso, indemnización alguna por la partida del gasto de adquisición de la mercancía. Frente a esta solución cabe preguntarse: ¿en qué medida hubiera sido procedente conceder indemnización, por este concepto, de haber sido pedida? La respuesta a esta pregunta depende de los remedios que utilice el comprador. Siendo el vendedor el obligado a indemnizar, tal indemnización debe tener en cuenta si el comprador ejercita o no otros remedios fundados en el incumplimiento del contrato de compraventa (resolución, rebaja del precio). Así son posibles tres situaciones: el comprador (i) solo pide indemnización de daños, (ii) resuelve el contrato y pide indemnización de daños, (iii) ejercita el remedio de la reducción del precio y pide indemnización de daños. Aunque nuestro caso es el primero vamos a considerar también brevemente lo que sucedería en los otros dos casos.

(i) Si el comprador no resuelve el contrato, como sucede en este caso, en principio es procedente indemnizar la partida del costo de adquisición de la mercancía, pero con las limitaciones que señalamos. El daño indemnizado es un daño emergente, fundado en la confianza en que la vendedora cumplirá el contrato (entregará una chatarra con nivel de cobre establecido en el contrato). De ese precio hemos de descontar (rebajar) el valor que tiene la mercancía recibida, sin la cualidad presupuesta en ella, de la que carece; por ejemplo, utilizada como simple chatarra de desecho. Pues el que no sirva para la finalidad presupuesta 
en el contrato no significa que no pueda servir para otro destino, que esté en la mano del comprador poder gestionar. Este valor deberá ser descontado de la partida indemnizatoria correspondiente al costo de adquisición.

(ii) Si el comprador hubiera resuelto el contrato, lo que no ocurre en este caso, como consecuencia de la restitución subsiguiente no habría incurrido en el costo de adquisición de la mercancía y, por tanto, no existiría esa partida indemnizable como daño. Y no por ello dejarían de ser indemnizables otros daños correspondientes al denominado interés positivo. Esta es la solución que se impone en el moderno derecho de contratos.

(iii) Si el comprador hubiera ejercitado el remedio de la rebaja del precio, cosa que tampoco ha ocurrido, no procedería tampoco pedir indemnización por el costo de adquisición de la mercancía. La reducción del precio (con matices, según se calcule) tiende a asignar a la mercancía adquirida el precio que realmente tiene como pura chatarra, sin el nivel de níquel presupuesto en el contrato, lo que hace que el comprador no tenga el daño. El remedio de la rebaja del precio es compatible con la indemnización de otros daños, distintos de los producidos por el menor valor de la cosa.

\subsection{GASTOS DE TRANSFORMACiÓN}

El comprador ha incurrido en gastos de transformación del total de las mercaderías adquiridas (para poderlas revender) por un monto de $\$ 75.000 .000$. Ese costo ¿debe serle reembolsado, tal como pretende? La Corte Suprema no le reconoce este derecho. Nosotros debemos preguntarnos si es o no adecuada tal desestimación.

Señala la vendedora que, atendida la importancia de la cualidad presupuesta para la compradora (nivel de níquel) esta debería haber desplegado toda la actividad necesaria que implica una mediana diligencia tendiente a cerciorarse de si la mercancía tenía la cualidad específica que en el fondo buscaba. Mas no lo hizo, y solo se percató de cómo era la mercancía una vez que le fuera denunciado el incumplimiento por la empresa estadounidense ${ }^{34}$.

Sin embargo, este argumento no llega a ser atendido por el Tribunal, que hace prevalecer la obligación. Y de ese modo, aplicando el artículo 1828 del Código Civil, entiende que la vendedora incurrió en cumplimiento imperfecto de su obligación de entrega.

Volviendo al argumento de la vendedora, lo primero que habría que preguntarse es, si la falta de conformidad de la mercancía estaba a la vista o se percibía en el proceso de transformación. De estarlo, tendría toda la razón la vendedora, pues la compradora no debería haber iniciado o proseguido este proceso, debiendo haber evitado incurrir en tales

\footnotetext{
34 Si bien nuestro Código civil, a diferencia de la CISG, no impone expresamente cargas de conducta al acreedor, como sería la de examinar la cosa objeto del contrato, es posible afirmar que el artículo 1546 no solo impone deberes de conducta al deudor contractual, sino también al acreedor, creándose una expectativa para el deudor, aunque incumplidor, respecto de la conducta que debiera observar la primera parte, la que coincide con la de una persona razonable en su lugar actuado conforme a la buena fe objetiva. De cualquier modo la carga de examen de las mercaderías no es extraña a nuestro derecho interno, desde que el Código de Comercio se la impone expresamente al comprador en su artículo 158. Sobre las cargas de conducta del acreedor, véase: VIDAL (2008) pp. 430-437.
} 
gastos. Pero, de no ser así, ¿puede la vendedora exigir a la compradora que inicie un proceso de verificación más bien costoso, sin que pueda confiar en las manifestaciones de la propia vendedora incorporadas al contrato?

Creemos que, en este caso, está justificada la confianza de la compradora en las declaraciones de la vendedora respecto de las cualidades de la mercancía vendida, en el momento de la celebración del contrato; y que puede seguir dejándose llevar por esa confianza en el momento de transformación de la mercancía. No es correcto que la vendedora exija a la compradora una verificación, para no tener que responder por la confianza creada, cuando la propia vendedora no la realizó antes de hacer las afirmaciones que suscitaron esta confianza.

(ii) La Corte Suprema que, como hemos visto, considera que la vendedora ha incumplido su obligación no admite la indemnización de los gastos de transformación por una razón diferente de la que podría resultar del argumento anterior de la vendedora. Esa razón vamos a encontrarla en el considerando decimosexto ya citado de la sentencia de reemplazo de la Corte Suprema, en los siguientes términos:

No procede acoger lo que se demanda como indemnización por[que] el corte de los rodillos es una acción realizada directamente por el comprador, y en todo caso es un costo propio del negocio que se realizaba por lo que no procede ser indemnizado de acuerdo con lo dispuesto en los artículos 1556 y 1558 del Código Civil.

La Corte Suprema utiliza como argumento desestimatorio, que el corte de los rodillos lo ha ejecutado directamente la compradora en su empresa y que el costo originado es un "costo propio" de la actividad que realiza.

Aunque la cuestión es delicada, creemos que es posible aportar algunos criterios orientados a una correcta solución jurídica. En principio, no debería ser un obstáculo para obtener la indemnización del costo de transformación, el que esta operación la haya realizado el comprador en su propia empresa, con propios medios, pues los medios empleados no por ser propios dejan de tener un costo, aunque sea inferior al que supondría encargar a un tercero la ejecución. Costo en el que se incurre con vistas a la obtención del beneficio que producirá la reventa. Si ese costo (esos recursos económicos propio empleados) resulta totalmente inútil o estéril, por no llegar a producir el beneficio, deberá ser indemnizado, en el marco de la responsabilidad contractual. Hemos dicho totalmente inútil. Pues si la transformación de los rodillos adquiridos resulta útil para un uso alternativo de los mismos, estaríamos pensando en un supuesto distinto, en el que, seguramente, no cabría pedir la indemnización de esta partida o podría resultar disminuida su cuantía.

Una vez que ha quedado claro que el comprador haya realizado la transformación de los rodillos en su propia empresa no es razón para pensar que no le causa una pérdida o daño, se abre otro problema: el cálculo del costo imputable a la ejecución de la tarea de transformación. Es una cuestión que dejamos abierta.

Para que el daño sea indemnizable en este caso hace falta, además, que se cumpla el requisito establecido en el artículo 1558 Código Civil: su previsibilidad para el vendedor, al tiempo de la celebración del contrato. 
En este punto la Corte Suprema admite que resultaba previsible la reventa de los rodillos:

La frustración de un negocio de esta naturaleza [la venta a la empresa estadounidense] parecía perfectamente previsible al tiempo de la celebración del contrato, para los efectos del artículo 1558 del Código Civil, pues era natural que la empresa compradora quisiera revender el material de chatarra que estaba adquiriendo”.

Sin embargo queda en la penumbra si la vendedora podía prever que los rodillos iban a ser transformados.

Se abre una cuestión: ¿la vendedora conocía o podía conocer en el momento de la celebración del contrato que la empresa compradora quisiera revender los rodillos adquiridos hacía necesaria su transformación? Es un paso más que el anterior; y recorrerlo, por la vía de la interpretación del contrato, encierra dificultades. Habría que acreditar que resultaba previsible para la vendedora que la reventa requería necesariamente la transformación previa de los rodillos ${ }^{35}$. La Corte Suprema no entra en este razonamiento porque sostiene, de modo discutible, que no ha existido daño.

(iii) Nos resta considerar una tercera cuestión. Si la Corte Suprema hubiera admitido la indemnización de los costos de transformación, ¿hubiera debido otorgarla por el total de ellos o solo por el costo correspondiente a la parte vendida a la empresa estadounidense? Es decir: 58 toneladas de las 1.500 compradas a la empresa vendedora. Cabe preguntarse: La vendedora ¿No actuó precipitadamente, cortando las 1.500 toneladas adquiridas, en vez de limitarse a las 58 vendidas?

Para responder a esta pregunta, debemos advertir, en primer lugar, que la compradora podía confiar en que las 1.500 toneladas tenían la concentración de níquel prometida, y en base a esto organizar su proceso de transformación en las condiciones que ella estimara más convenientes. Y, seguramente, el costo sería menor si se transformaba toda la partida.

No obstaculiza la indemnización del costo total de transformación el hecho de que la compradora no pueda acreditar que hubiese vendido las 1.500 toneladas a la empresa norteamericana; con tal que pudiera haberlas vendido a otros compradores, por existir demanda de esa mercancía. De no ser así, de no darse ninguna de estas premisas, podría ser considerado que el costo de la transformación del total de la mercancía, por encima de la cantidad vendida a la empresa americana, debería ser asumido por la compradora. La compradora no debe reclamar a la vendedora como daño emergente, gastos que no sean razonables teniendo en cuenta las circunstancias antedichas.

\subsection{LUCRO CESANTE INDEMNIZABLE: EL PRECIO NO COBRADO O LA FRUSTRACIÓN DE LA} REVENTA

Nos referimos ahora a la indemnización por la pérdida del beneficio de la reventa de la mercancía comprada, a consecuencia de su falta de conformidad. Vamos a distinguir dos

35 La previsibilidad del uso que le iba a dar la empresa vendedora se sigue, además, del hecho que en el proceso de negociación el representante de la vendedora, a solicitud de la compradora, envío un correo electrónico indicando el detalle de los componentes de los rodillos, los que contaban, entre otros, con un alto índice de níquel. 
partidas: el beneficio correspondiente a las 58 toneladas inicialmente vendidas a la empresa norteamericana, y el que se refiere la al resto de la mercancía (1.500 toneladas). La demandante solicita indemnización por la pérdida del beneficio de ambas partidas; pero la Corte Suprema solo la concede por la primera, pero no por la segunda.

(i) Podemos constatar que la primera partida fue objeto de consideración por parte de la Corte Suprema. Así se desprende del considerando decimoctavo de su sentencia de reemplazo, en los siguientes términos:

(...) de los cuales (los antecedentes) se puede concluir que efectivamente la demandante vio frustrado un negocio de venta de rodillos con la empresa Triorient INC, de los Estados Unidos de Norteamérica, por un total de facturación de US \$330.000. Este negocio no prosperó, porque los rodillos en cuestión carecían de la composición de Níquel requerido por la compañía norteamericana. De acuerdo con estos antecedentes, y con la declaración del demandante en su escrito de demanda, la utilidad que debía arrojar este negocio a la fecha de presentación de la demanda era de $\$ 114.400 .000$, monto que estima perfectamente como beneficio o utilidad del negocio y, por lo mismo, se concederá una indemnización por este rubro, más los reajustes e intereses corrientes para operaciones no reajustables, desde el día de presentación de la demanda hasta el día de pago efectivo. La frustración de un negocio de esta naturaleza parecía perfectamente previsible, al tiempo de celebrar el contrato, para los efectos del artículo 1558 del Código Civil, pues, era natural que la empresa compradora quisiera revender el material de chatarra que estaba adquiriendo".

(ii) La compradora también intenta en su demanda la indemnización de las ganancias que habría obtenido de la reventa del resto de las mercaderías a la misma empresa estadounidense. Se funda en que la falta de conformidad de la primera partida impidió que se materializara la reventa del resto de la mercancía, verbalmente comprometida ${ }^{36}$. La Corte suprema rechaza esa pretensión y limita la indemnización a la pérdida del beneficio de la reventa de la primera partida.

Para saber si es o no adecuada esta decisión de la Corte suprema, debemos dar respuesta a algunas preguntas, referidas a hechos que integrarían el este caso el supuesto del deber de indemnizar:

(1) En la relación de la demandante con la empresa estadounidense, ¿existía un verdadero contrato de suministro, referido al total de la mercancía, o solo meras expectativas de una ampliación de la venta inicial, circunscrita a la primera partida?

\footnotetext{
36 En la sentencia de primera instancia se lee: "El daño inicial se materializa en haber perdido toda posibilidad de seguir manteniendo relaciones comerciales con la empresa americana Triorient Trade Inc., con quienes existía la posibilidad real y compromisos ya adquiridos de manera verbal de continuar con la venta del resto de los rodillos comprados a la Siderúrgica Huachipato S.A., lo que a todas luces y de manera evidente se vio frustrado. Estas ventas iban a generar a la parte demandante un ingreso promedio a la fecha, de US $\$ 2.000 .000$ (dos millones de dólares aproximadamente)".
} 
Aunque la demandante se refiera a un compromiso verbal de adquisición no parece que quedara suficientemente acreditada la existencia de una verdadera venta, frustrada por la falta de conformidad. Si hubiera existido, la demandante podría reclamar la pérdida del beneficio que le habría proporcionado; pero no siendo así, resulta más difícil fundamentar la indemnización sobre la base meras expectativas comerciales.

(2) Hay otra razón para justificar la indemnización del lucro cesante correspondiente a la reventa de la segunda partida: la existencia de un mercado que ofrezca alta probabilidad de reventa de la mercancía adquirida. De existir ese mercado y haberse frustrado la reventa en él por la falta de conformidad, la indemnización del lucro cesante de la segunda partida estaría justificada y debería ser calculada conforma al precio de ese mercado.

Para poder reconocer de este modo la indemnización del lucro cesante hubiera sido necesario que la demandante lo hubiera justificado así. No lo hizo, sino que fundamentó el daño (lucro cesante) en la expectativa, más o menos cierta, de la compra total de la mercancía por la empresa norteamericana. Hubiera sido necesario, además, que hubiera probado la existencia de ese marcado que le hubiera proporcionado la ganancia, y el precio que la mercancía hubiera tenido en el mismo, en el que podría haber sido vendida.

Podemos admitir que no esté probado que el contrato con la empresa norteamericana comprendiera todas las mercaderías y que sean meras expectativas de la compradora y eso puede justificar que, en ese entendido, no se le conceda la indemnización. Pero queda abierta la otra alternativa y cabe preguntarse ¿por qué no se midió la indemnización, considerando el precio de mercado? La respuesta más probable quizás deba ser esta: porque la demandante no lo solicitó de esa manera, ni suministró la prueba de la posibilidad de una venta en un mercado, a un determinado precio. La compradora demandó la indemnización de esta partida, basándose exclusivamente en la expectativa, más o menos cierta, de la compra total de las mercaderías por su comprador norteamericano.

\section{CONCLUSIONES}

Procedemos en el mismo orden que se desenvuelve en el cuerpo del comentario.

1. La determinación del objeto que se obliga a entregar el vendedor puede quedar determinada en el instrumento contractual exclusivamente o, como en este caso, resultar más compleja, debiendo acudir a documentos y declaraciones emitidas durante la negociación del acuerdo y llegar a ella por vía de interpretación.

2. La demandada, aunque sin éxito señaló que la acción de daños estaba prescrita, pues era aquella correspondiente a los vicios redhibitorios. El Tribunal señaló que esa no era la acción que se había ejercido, por lo mismo, no acogió dicha alegación. Sin embargo, no se pronunció sobre dos puntos: ¿existía concurso entre remedios generales y la disciplina de la acción redhibitoria? Y, en segundo lugar, ¿cuál es la plazo de prescripción de la acción de daños del artículo 1861? Probablemente, la respuesta a lo primero sea que no existía concurso, pues no se trataba de un "uso natural de la cosa”. En segundo lugar, tanto los tribunales como la doctrina mayoritaria parecen entender actualmente que la acción de daños ex artículo 1861 tiene un plazo de 
prescripción independiente de la redhibitoria o de la quanti minoris, quedando sometido a las reglas generales.

3. La idea de incumplimiento utilizada por la Corte integra manifestaciones de disconformidad tratándose de una obligación de especie o cuerpo cierto, lo cual, aunque aún tímidamente, la aproxima a una noción amplia y unitaria de incumplimiento. Por otra parte, determinar la integración del destino de la cosa a la obligación de entrega puede ser una operación compleja en la que la buena fe ha de prestar su auxilio.

4. Haciendo eco de una tendencia bien asentada ya, la sentencia reconoce la autonomía de la pretensión indemnizatoria y, en primer lugar, la justifica en las reglas del pago. Por otra parte, la indemnización no corresponde, exactamente, a un cumplimiento por equivalencia, sino, más precisamente, a la satisfacción del propósito práctico del contrato y, por consiguiente, del interés del acreedor.

5. Con respecto al cálculo de la indemnización, hemos de distinguir hipótesis diversas, según si se ha pagado el precio completo y se ha incurrido en los gasto de transformación o no. Esto nos permite evaluar la partidas indemnizatorias concedidas o denegadas en este caso.

6. ¿Resulta correcto el cálculo en lo relativo al daño emergente y el lucro cesante? Nuestra opinión es que no, no del todo al menos. Así, tratándose de los costos de adquisición resulta necesario compensarlos con el valor que tenga la mercancía en poder de la compradora. Con respecto a los gastos de transformación, la Corte señala que no deberían indemnizarse, sin embargo, se trata de un costo incurrido determinado por la confianza que generó la vendedora en la posible reventa. Finalmente, por lo que toca al lucro cesante, la Corte no considera la posibilidad de revender alrededor de 1.000 toneladas de rodillos de laminación, sin embargo, en la medida en que estuviera suficientemente acreditado que la empresa norteamericana (u otra) iba a comprar la cantidad completa no se advierte por qué no constituiría lucro cesante.

\section{BIBLIOGRAFÍA CITADA}

Alcalde Silva, Jaime (2008): “La causa de la relación obligatoria”, en GuZmán Brito, Alejandro (editor), Estudios de Derecho civil III (Santiago, LegalPublishing), pp. 339-394.

Alessandri Rodríguez, Arturo (2003): De la compraventa y de la promesa de venta (Santiago, Editorial Jurídica de Chile).

Bahamondes Oyarzún, Claudia (2011): "Concurrencia de la indemnización de daños y la pretensión de cumplimiento específico frente al incumplimiento contractual, Incumplimiento Contractual, Nuevas Perspectivas", Cuadernos de Análisis Jurídico, Vol. VII, pp. 235-262.

BARAONA GonZÁlez, Jorge (1997): "Responsabilidad contractual y factores de imputación de daños: apuntes para una re-lectura en clase objetiva”, Revista Chilena de Derecho, Vol. 24, No 1, pp. 151-177.

Beltrán Heredia y Castaño, José (1956): El Cumplimiento de las Obligaciones (Madrid, Editorial Revista de Derecho Privado). 
Carrasco Perera, Ángel (2010): Derecho de contratos, Aranzadi (Madrid).

Corral Talciani, Hernán (2010): Contratos y Daños por Incumplimiento (Santiago, AbeledoPerrot).

De la MaZA, Iñigo (2011) "El concurso entre el error con trascendencia anulatoria y el incumplimiento resolutorio", en De la Maza Gazmuri, Iñigo (coord.) Incumplimiento contractual: nuevas perspectivas, Cuadernos de Análisis Jurídicos, Colección de Derecho Privado VII. Capítulo (Iñigo), U. Diego Portales, Santiago, pp. 213-234.

Díez-Picazo y Ponce de León, Luís (2008): Fundamentos de Derecho Civil Patrimonial. Relaciones Obligatorias, II, $\sigma^{a}$ ed. (Navarra, Civitas).

Fenoy Picon, Nieves (2006): El sistema de protección del comprador (Madrid, Colegio de Registradores de la Propiedad y Mercantiles de España).

Fueyo Laneri, Fernando (2004): Cumplimiento e Incumplimiento de las Obligaciones (Santiago, Editorial Jurídica de Chile).

Gatica Pacheco, Sergio (1959): Aspectos de la indemnización de daños por incumplimiento del contrato: del incumplimiento de las obligaciones contractuales; de los daños y de su liquidación judicial, legal y convencional. De la cláusula penal. Artículos 1556, 1558, 1559 y 1535 a 1544 del Código Civil (Santiago, Editorial Jurídica de Chile).

Gregoraci Fernández, Beatriz (2011): “The Achilleas: la remoteness rule sometida a debate en la House of Lords”, Cuadernos de Análisis Jurídico, Vol. VII, pp. 295-311.

GuZMÁn BRITo, Alejandro (2007): "Sobre la relación entre las acciones de saneamiento de los vicios redhibitorios y las acciones comunes de indemnización, con especial referencia a su prescripción", Revista Chilena de Derecho Privado, No 9, pp. 95-120.

López Díaz, Patricia Verónica (2010): "La indemnización compensatoria por incumplimiento de los contratos bilaterales como remedio autónomo en el Derecho civil Chileno", Revista Chilena de Derecho Privado No 15, pp. 65-114.

Morales Moreno, Antonio (2012): “Tres modelos de vinculación del comprador en las cualidades de la cosas", Anuario de Derecho Civil, Vol. 65, Nº 1, pp. 5-28.

Morales Moreno, Antonio Manuel (2010), Incumplimiento del contrato y lucro cesante (Cizúr Menor [Navarra] Thomson Reuters).

Morales Moreno, Antonio Manuel (1983): "El "propósito práctico" y la idea de negocio jurídico en Federico de Castro", Anuario de Derecho Civil, Vol. 36, No 4, pp. 1.5291.546.

Morales Moreno, Antonio Manuel (1980): "El alcance protector de las acciones edilicias", Anuario de Derecho Civil, Vol. 33, No 3, pp. 585-686.

Pantaleón, Fernando (1993): "Las nuevas bases de la responsabilidad contractual", en Anuario de Derecho Civil, Vol. 46, № 4, pp. 1.719-1.746.

RÉmY, Philippe (1997): "La responsabilité contractuelle: histoire d'un faux concept", Revue Trimestrielle de Droit Civil, No 2, pp. 323-355.

SAIDov, Djakhongir (2008): The Law of Damages in International Sales: The CISG and other international instruments (Portland, Hart Pub.).

Vidal Olivares, Álvaro (2014): "La indemnización de daños por incumplimiento y estar contractualmente obligado", en Turner, Susan y VAras Braun, Juan Andrés (coords.) Estudios de Derecho Civil IX, pp. 711-742. 
Vidal Olivares, Álvaro (2014): "El incumplimiento y los remedios del acreedor en la Propuesta de Modernización del Derecho de las Obligaciones y Contratos español”, Revista Chilena de Derecho Privado, N 16, pp. 243-302.

Vidal Olivares, Álvaro (2008): "La carga de mitigar las pérdidas por el acreedor y su incidencia en el sistema de remedios por incumplimiento”, en GUZMÁn BRITO, Alejandro (editor), Estudios de Derecho Civil III (Santiago, LegalPublishing), pp. 429-457.

Vidal Olivares, Álvaro (2006): La protección del comprador. Régimen de la Convención de Viena y su contraste con el Código Civil (Valparaíso, Ediciones Universitarias de Valparaíso).

\section{JURISPRUDENCIA CITADA}

AGF Alliance Chile Compañia de Seguros Generales S.A. con LeTourneau INC (2008): Rol 8115-2008 (Indemnización por vicios redhibitorios).

Cecinas La Preferida S.A. con, Comercial Salinak Limitada (2005): Corte Suprema, 27 de julio de 2005 (Resolución de contrato. Indemnización de perjuicios procedente. Entrega de producto distinto al convenido. Compraventa), cita Westlaw/3930/2005.

Glide Diversiones Limitada con Compañia de Inversiones y Desarrollo Sur S.A (2008): Corte Suprema, 19 de mayo de 2008 (Arrendamiento, obligaciones del arrendador, incumplimiento, terminación del contrato). Cita online: CL/JUR/5837/2008.

José Ampuero Asencio con Alfonso Castillo Hernández (2013): Corte Suprema, 28 de enero de 2013 (incumplimiento contractual autonomía de la acción indemnizatoria). Cita online: CL/JUR/174/2013.

Silva Escandón María Gabriela contra Dosque Contreras María Luisa (1993): Corte de Apelaciones de Concepción, 1 de diciembre de 2003 (Compraventa. Obligaciones del vendedor. Saneamiento de la evicción. Tradición. Embargo) cita Westlaw Chile: CL/ JUR/66/1993.

Zorin S.A. con Compañia Siderúrgica Huachipato S.A. (2012): Corte Suprema, 31 de octubre de 2012 (cumplimiento imperfecto en contrato de compraventa de mercancías) Cita online: CL/JUR/2412/2012. 